\title{
Boehringer, Monika, dir. Anthologie de la poésie des femmes en Acadie. Introduction
}

\section{Monika Boehringer. Préface Nicole Brossard. Moncton : Perce-Neige, 2014. 265 p.}

Cette anthologie plaira aux lectrices et lecteurs pour deux raisons. Tout d'abord, elle offre une excellente sélection de poèmes chez les auteures acadiennes des vingtième et vingt-etunième siècles. Les choix effectués par Monika Boehringer répondent à deux critères : la qualité des textes et leur représentativité dans la carrière de chaque auteure. Les vingt-sept écrivaines sont Joséphine Duguay (sœur Marie-Augustine), Athela Cyr, Anna Malenfant, Antonine Maillet, Edith Butler, Angèle Arsenault, Annick Perrot-Bishop, Germaine Comeau, Hélène Harbec, Huguette Bourgeois, Rose Després, Gracia Couturier, France Daigle, Edith Bourget, Dyane Léger, Martine L. Jacquot, Pauline Dugas, Marie-Claire Dugas, Judith Hamel, Brigitte Harrison, Georgette LeBlanc, Emma Haché, Cindy Morais, Stéphanie Morris, Sarah Marylou Brideau, Marie-Eve Landry et Monica Bolduc. Certaines sont plus connues, parfois dans un genre différent, que d'autres. La première est née en 1896, la plus jeune en 1992. Toutes prennent l'écriture au sérieux et par passion. Parmi elles, Duguay, Maillet, Perrot-Bishop, Harbec, Després, Daigle, Léger, Jacquot, Hamel et Haché occupent une position substantielle.

Dans une introduction exemplaire, Boehringer développe une synthèse fournie de la place et de l'évolution de la poésie des auteures acadiennes, particulièrement à partir de 1949 lorsque l'enseignement supérieur s'ouvre aux femmes. Très pertinemment, elle y ajoute une fine comparaison avec la littérature au féminin du Québec et ses anthologies, en particulier l'Anthologie de la poésie des femmes au Québec : des origines à nos jours de Nicole Brossard et Lisette Girouard.

Bien que les poètes représentées soient issues d'horizons fort divers et que l'ouvrage ne soit pas de nature thématique, celui-ci privilégie des textes forts et résolus dans leur ton. Les lectrices seront sans doute frappées par l'énergie et la clarté des voix exprimées. De fait, «le bouquet de signes » que Boehringer rassemble pour notre plus grand plaisir, dégage une unité à ce corpus acadien autre que simplement historique ou géographique, à savoir l'unité de la force : «Cette poésie a de multiples racines, dans le ciel et dans la terre - non dans un territoire compris de façon nationaliste, mais dans un coin de pays exproprié » et «a su se frayer un chemin ». Quel que soit le sujet - l'histoire acadienne, la vie quotidienne, l'amour, la foi, l'égalité des sexes cette anthologie unit de nombreuses exhortations, paroles courageuses et encourageantes. Dans 
ses pages, ce type d'écriture n'a rien de doctrinaire ; il promet ici un régal aux lecteurs au fil de poèmes éloquents, exigeants, avides.

Une place de choix est accordée à Léger, dont les «images d'une violence inouïe se juxtaposent à des éléments ludiques et plus légers, suivis de visions surréelles »; les extraits proviennent de Graines de fées (1980), des Anges en transit (1992), de Comme un boxeur dans une cathédrale (1996) et du Dragon de la dernière heure (1999). Autre « révoltée », Després énonce «une réaction virulente contre l'Acadie d'antan » avec Fièvre de nos mains (1982), Requiem en saule pleureur (1986), Gymnastique pour un soir d'anguilles (1996), La vie prodigieuse (2000) et Si longtemps déjà (2009). Dans l'anthologie de Boehringer, certains poèmes convainquent par l'intertextualité littéraire qu'ils transportent et reformulent, qu'il s'agisse, entre autres, d' «Ode à Cassandre» de Pierre de Ronsard et de «Rondeau de printemps » de Charles d'Orléans dans «Première neige » de Duguay (1928) ou d' « Il pleure dans mon cœur » de Paul Verlaine dans «Il pleut» (2013) de Daigle. Pour les poèmes traitant de la situation des femmes, tout aussi bien, par exemple, dans «Causerie masculine » (1943) de la religieuse Marie-Augustine en réponse à «Causerie féminine » du poète québécois Albert Lozeau, que dans «Présentation de la marchandise » (2010) chez Haché qui s’élève contre l'abus sexuel, ou dans le lapidaire «Tu vas être belle ou 'The twisted code of women' » (2014) de Bolduc, l'exhortation est volontiers accusatrice et magistralement formulée. L'exhortation, c'est aussi le monologue secret qui ordonne la vie de l'une ou l'autre protagoniste et y décèle un charme durable au rythme des saisons et de la maison, ainsi chez Harbec et Harrison. Que la langue soit soutenue (voir, par exemple, l'exquise écriture de Perrot-Bishop) ou familière (comme dans le style alerte et cadencé de Le Blanc), cette Anthologie de la poésie des femmes en Acadie se lit avec autant de ferveur que le « fracas d'un géranium, / ébouriffé de rouge » (PerrotBishop).

Catherine Parayre, Université Brock 